Max-Planck-Institut für demografische Forschung Max Planck Institute for Demographic Research Konrad-Zuse-Strasse 1 - D-18057 Rostock · GERMANY

Tel +49 (0) 3812081 - 0; Fax +49 (0) 3812081 - 202;

http://www.demogr.mpg.de

MPIDR WORKING PAPER WP 2004-016

MAY 2004

\title{
Does the impact of socioeconomic status on mortality decrease with increasing age?
}

Rasmus Hoffmann (hoffmann@ demogr.mpg.de)

This working paper has been approved for release by: James W. Vaupel (jwv@ demogr.mpg.de) Head of the Laboratory of Survival and Longevity.

(C) Copyright is held by the authors.

Working papers of the Max Planck Institute for Demographic Research receive only limited review. Views or opinions expressed in working papers are attributable to the authors and do not necessarily reflect those of the Institute. 
Does the impact of the socioeconomic status on mortality decrease with increasing age?

Rasmus Hoffmann (PhD Student)

Max-Planck-Institute for Demographic Research

Rostock, Germany

May 132004 


\begin{abstract}
The impact of SES on mortality is an established fact. I examine if this impact decreases with increasing age. Most research finds that it does so but it is unknown whether this decrease is due to mortality selection. The data I use come from the US-Health and Retirement Study, which surveyed 9376 persons aged 59 and over from 1992 to 2000. The variables allow for a time varying measurement of SES, health and behavior. Eventhistory-analysis is applied to analyze differences in mortality rates. My results show that socioeconomic mortality differences are stable across ages whereas they clearly decline with decreasing health. My first finding, that health rather than age is the equalizer combined with the second finding, that good health itself is unequally distributed, leads to the conclusion that in old age, the impact of SES is transferred to the health status and hence it is stable across ages.
\end{abstract}




\section{Introduction:}

The impact of the socioeconomic status (SES) on health and mortality has been observed many times in mortality research. Poor groups of people have generally two to three times higher death rates than rich ones (Auerbach and Krimgold 2001:31). The difference in life expectancy for Dutch men between the highest and lowest educational group is 4 years (Stronks 1997:3). In the 1980s, white men in the USA with a family income lower than $10.000 \$$ had a 6.6 years lower life expectancy than those with an income higher than 25.000\$ (Smith 1999:147). Within-country differences are at times much higher than international differences, e.g. the male mortality rate of those aged under 65 is higher in Harlem, New York, than it is in Bangladesh, India (McCord and Freeman 1990).

In spite of overall decreasing mortality levels, economic growth and improvements in medicine, mortality differentials between income groups and educational groups increased at ages 25 to 64 between 1960 and 1986 in the USA (Pappas et al. 1993:103). In the 1980s, this was also the case for all countries for which data are available (Valkonen 2001:8826).

Increasing differences here means increasing relative differences. Absolute differences, by contrast, may have decreased because of the overall declining level of mortality. However, results for the USA indicate that lower class mortality did not decline at all, which means that even absolute differences have increased (Auerbach and Krimgold 2001).

There is an ongoing debate about the causality of these mortality differentials. Some authors assume that health inequalities arise prior to differences in SES and that especially in later working ages the health status translates into SES via the ability to work (Smith 1999). In the following, I will leave this question aside and assume that the main direction of causality goes from SES to health and that the notion of " SES impact on health and mortality" is thus generally justified. The concrete pathway of this impact will be further illustrated below.

While socioeconomic differences in health and mortality are well established by research findings, it is unclear whether these differences are stable across the life course or 
whether they decrease in old age. The latter is the most common finding made by researchers and has been explained using the following arguments:

1. Aging works as a leveler of social differences because biological processes assume dominance over social determinants and eventually everybody must die, regardless of social class (Liang et al. 2002:295).

2. The welfare state reduces socioeconomic differences in old age through benefits and social policy.

3. The impact of past experiences that are responsible for health differences, e.g. working conditions, fades out at old age.

4. The observed mortality differences get smaller in old age on the aggregate level because the surviving population is more homogeneous due to selective mortality.

The last argument means that the impact of SES on mortality on the individual level can be stable or even increases with age. This opposite result is based on the following assumptions:

5. The impact of past unhealthy experiences, e.g. unhealthy working conditions and smoking, is postponed to older ages.

6. Past experiences, e.g. education, accumulate and may interact with other factors, e.g. economic and social capital. The health outcome of this accumulation is incorporated into the "health stock" (for a discussion of arguments 2 to 6, see Ross and Wu 1996:107).

7. Vulnerability increases in old age and makes differential exposures more harmful (House et al. 1994:221).

The theoretical background of this research is the question whether the interplay between social and biological factors in determining health and mortality of an individual is changing over the life course or not. Another related question is how we can understand social inequality in old age. Health may become so important for the living conditions 
and quality of life that it becomes an important aspect of social inequality. My study aims at finding out whether the impact of socioeconomic status decreases with age or not and to what extent the connection between SES and mortality is mediated by the health status.

To motivate the choice of variables and models in the empirical part of this paper, I will give an overview of possible causal pathways from SES to mortality. According to the majority of studies, material factors are responsible for a large part of socioeconomic mortality differences. Money can buy healthy food, good housing, better medical treatment and other goods that are directly or indirectly relevant to maintaining a good health status. Education is important to get knowledge about health risks and healthy behavior. Social capital is helpful when a person needs information, connections, and emotional and practical help.

Stress and behavior are factors that are on an intermediate level between SES and mortality. Stress is likely to be higher and health behavior is poorer in lower status groups. Finally, on the societal level the health care system is an important factor that has an influence on whether a low status can cause poor health and higher mortality or not (Davey Smith et al. 2001; Kunst 1997).

\section{Data:}

My data come from the US Health and Retirement Study (HRS) and the study of Assets and Health Dynamics among the oldest old (AHEAD). These are two representative studies conducted by the Institute of Social Research (ISR), University of Michigan, that were started separately in 1992 and 1993 respectively and then combined in 1998 with a follow-up every second year (Soldo et al. 1997). Since HRS focuses on retirement ages and AHEAD on ages of 70+, I merged them with the help of some data sets prepared by RAND (for information see http://hrsonline.isr.umich.edu and http://hrsonline.isr.umich.edu/meta/rand).

This resulted in a sample of 9376 persons born before 1934 (aged 59 to 107) surveyed from 1992 to 2000, with 2608 deaths during observation. I excluded black persons from the analysis. Institutionalized persons were already excluded in the original baseline 
sample (but surveyed in the institution during the follow up interviews). This may cause a bias. For example, single persons, persons with poor health and women are more likely to be in a nursery home and thus they are more likely to be underrepresented in the sample (Grundy and Sloggett 2003:936).

The variables allow a detailed and time varying measurement of SES, health status and some control variables. The variables in the following list are time varying if not indicated otherwise.

\section{Variables:}

Education is measured in years of education (time constant, levels 0-7,8-15,16+).

Wealth includes all assets of the household in which the person lives (bank account, real estate, shareholdings etc.) and is measured on three levels: lowest quartile, second lowest quartile and above median wealth.

Income is the net annual household income divided by a weighted number of persons living in the household (net equivalent income). The weight is 1 for the first person and 0.7 for all other persons in the household. Income is also measured on three levels: lowest quartile, second lowest quartile and above median income.

Parents' mean age at death is the mean age at death of both parents (time constant, levels $-75,76+)$. Under certain conditions, it captures the genetic constitution that is transferred from the parents to their children; see discussion section.

Children is an indicator for any own children (time constant, levels yes, no). This variable measures partly social capital, namely if it is possible that a child looks after the old person, but it can not be treated as a social status variable. This is because it measures many different things. For example, having numerous children is an indicator of low social status and may be the cause for higher mortality whereas having no children may be the consequence of bad health (Doblhammer 2000).

Labor force status. This variable differentiates between working, being retired/disabled and not being in the labor force. While the labor force status is to a large extent a function of age and health (which I control for by using other variables), it 
additionally captures other information on social status and every-day life information that is predicting mortality.

Marital status is not a social status measure in a strict sense. Firstly, marital status depends partly on social status, e.g. persons with a relatively low social status are more likely to live alone. Secondly, marital status has a high impact on the social status in the sense that divorce or widowhood is often followed by a loss of economic and/or social capital. In this analysis I combine the divorced with the never married persons because these are both very small groups which show a similar level of mortality.

Health behavior is an index focusing on a) physical activity, b) being an ex-smoker and c) a current smoker.

Self-rated health. Question on self-rated health are asked in the traditional way, with five provided categories of answers. I merged the first two categories "excellent" and "very good".

Objective health is another index that includes a) being in a hospital for more than 10 days per year, b) limitations in activities of daily living (ADL), c) body mass index (BMI) at baseline $<21.4$ for men and $<19.5$ for women (=lowest decile) and d) loss of weight of more than 10 per cent between two waves (= two years).

Age is controlled for using four age groups (59-69, 70-79, 80-89, 90+)

Some variables have been tested in previous models and than skipped because they did not show significant results after controlling for other variables. The omitted variables are: occupational group, parents' education, going to church, children living nearby, drinking, high BMI, gaining 10 per cent of body weight.

\section{Methods:}

I apply event-history-analysis with a model for the force of mortality. This includes a baseline for the basic time variable age that is piecewise linear. The results shown are computed with STATA 8 and aML 2.04. The baseline for age covers the age range from 59 to 107 whereas the observation period is only 8 years, namely from 1992 to 2000. 
Thus, the cohorts are not real cohorts but partly synthetic ones in the sense that in spite of the longitudinal data, no individual in the data set is really observed from age 59 to ages above 67. Different models are used in different steps to analyze the causal relationships between the predictor variables and the mortality rate including different interactions and heterogeneity. A general formula for the model is:

$$
\ln \mu_{i}(x)=y(x)+\sum_{j} \alpha_{j} X_{i j}+\sum_{k} \beta_{k} W_{i k}(x)+\sum_{\{l, m:(l, m) \neq(1,1)\}} \chi_{l m} I\{A=l, B(x)=m\}+U_{i}
$$

where $\mathrm{y}(\mathrm{x})$ is the baseline hazard that depends on age, $\mathrm{X}$ is a matrix of time constant variables and $\mathrm{W}$ denotes a matrix of time-varying variables that depend on age. The fourth term represents an interaction between a time constant and time varying variable, A and $\mathrm{B}$, where $I$ is an indicator that equals 1 for one specific combination of the levels of the two variables and that equals 0 otherwise. $U$ stands for a heterogeneity term that is assumed to measure an individually constant frailty in the sample.

\section{Results:}

Table 1 shows relative risks. The underlying models are without interactions and separate for men and women. The absolute baseline risk for the four age groups is not shown. The baseline risk roughly doubles from one age group to the next, i.e. with every ten years of age. Model 1 only contains the univariate results of each variable separately. All variables show the expected association with mortality and all of them are significant, except marital status. The latter is not significant for women. Having children is not significant for men and, surprisingly, men with 8 to 15 years of education do not have a significantly lower mortality compared to those with 0 to 7 years of education. 
Table 1: Event history model for mortality

\begin{tabular}{|c|c|c|c|c|c|c|c|}
\hline & & \multicolumn{2}{|c|}{ MODEL 1} & \multicolumn{2}{|c|}{ MODEL 2} & \multicolumn{2}{|c|}{ MODEL 3} \\
\hline & & male & female & male & female & male & female \\
\hline \multirow[t]{2}{*}{ parents' death age } & -75 & 1 & 1 & & & 1 & 1 \\
\hline & $76+$ & $0.86^{* \star *}$ & $0.77^{* * *}$ & & & 0.92 & $0.87^{* *}$ \\
\hline \multirow[t]{3}{*}{ education } & $0-7$ & 1 & 1 & 1 & 1 & 1 & 1 \\
\hline & $8-15$ & 0.94 & $0.78^{* * *}$ & 1.20 ** & 0.92 & $1.37^{* * *}$ & 1.03 \\
\hline & $16+$ & $0.59^{\star \star *}$ & $\left.0.63^{(* \star}\right)$ & 0.99 & 0.86 & $\left.1.311^{* \star}\right)$ & 0.94 \\
\hline \multirow[t]{2}{*}{ children } & no & 1 & 1 & 1 & 1 & 1 & 1 \\
\hline & yes & 0.93 & $0.83^{* *}$ & 0.98 & $0.85^{* *}$ & 0.99 & $0.87^{*}$ \\
\hline \multirow[t]{3}{*}{ labor force status } & work & 1 & 1 & 1 & 1 & 1 & 1 \\
\hline & retired/disabled & $2.48^{* * *}$ & $3.36^{* * *}$ & 2.24 *** & 3.02 *** & $1.54^{* * *}$ & $2.17^{* \star *}$ \\
\hline & not in labforce & $3.17^{\star \star *}$ & $1.83^{* \star *}$ & $2.54^{\star \star *}$ & $1.63^{* \star}$ & $1.97^{\star *}$ & 1.20 \\
\hline \multirow[t]{3}{*}{ marital status } & married & 1 & 1 & 1 & 1 & 1 & 1 \\
\hline & widowed & 1.05 & 1.10 & 0.95 & 0.90 & 1.01 & 0.91 \\
\hline & divorced/never & $1.46^{* * *}$ & 1.17 & $1.25^{* *}$ & 0.80 * & 1.22 * & $0.77^{* *}$ \\
\hline \multirow[t]{3}{*}{ wealth (percentiles) } & $0-25$ & 1 & 1 & 1 & 1 & 1 & 1 \\
\hline & $25-50$ & 0.88 * & $0.71^{* * *}$ & 0.92 & $0.78^{* \star *}$ & 1.05 & 0.91 \\
\hline & $50-100$ & $0.54^{* * *}$ & $0.57\left(^{* * *}\right)$ & $0.65^{* * *}$ & $0.72\left(^{* * *}\right)$ & $0.87\left(^{*}\right)$ & 0.90 \\
\hline \multirow[t]{3}{*}{ income (percentiles) } & $0-25$ & 1 & 1 & 1 & 1 & 1 & 1 \\
\hline & $25-50$ & $0.75^{* * *}$ & $0.60^{* * *}$ & 0.86 ** & $0.67^{* * *}$ & 0.95 & $0.75^{* * *}$ \\
\hline & $50-100$ & $0.52^{* * *}$ & $0.54\left(^{* * *}\right)$ & $0.72\left(^{* * *}\right)$ & $\left.0.65^{(* * *}\right)$ & $0.82\left({ }^{* *}\right)$ & $0.74\left(^{* * *}\right)$ \\
\hline \multirow{3}{*}{$\begin{array}{l}\text { health behaviour } \\
\text { (act,exsmoke,smoke) }\end{array}$} & good & 1 & 1 & & & 1 & 1 \\
\hline & fair & $2.21^{* * *}$ & 3.34 *** & & & $1.73^{* * *}$ & $2.40^{* * *}$ \\
\hline & poor & $4.38^{* \star *}$ & $4.62\left(^{\star \star \star}\right)$ & & & $\left.2.78^{(\star \star \star}\right)$ & $2.95\left(^{(\star \star}\right)$ \\
\hline \multirow[t]{4}{*}{ self rated health } & excel/very good & 1 & 1 & & & 1 & 1 \\
\hline & good & $1.58^{* * *}$ & $1.65^{* * *}$ & & & $1.32^{* * *}$ & $1.44^{* * *}$ \\
\hline & fair & $2.60^{* \star *}$ & $2.68^{* * *}$ & & & $1.85\left(^{* \star \star}\right)$ & $1.92\left(^{* * *}\right)$ \\
\hline & poor & $6.11^{* * *}$ & 4.52 *** & & & $3.38^{* * *}$ & $2.6\left(^{* * *}\right)$ \\
\hline objective health & excel/very good & 1 & 1 & & & 1 & 1 \\
\hline \multirow[t]{3}{*}{ (Hospital,adl,thin,loss) } & good & $2.08^{* * *}$ & $1.76^{* * *}$ & & & $1.36^{* * *}$ & 1.22 *** \\
\hline & fair & $3.56\left(^{(\star \star}\right)$ & $3.43^{* \star *}$ & & & $1.74\left(^{\star \star \star}\right)$ & $1.98^{* * *}$ \\
\hline & poor & $5.03\left({ }^{* \star \star}\right)$ & $4.77\left({ }^{* \star \star}\right)$ & & & $2.27\left(^{\star \star \star}\right)$ & $\left.2.39^{(\star \star *}\right)$ \\
\hline
\end{tabular}

Stars in brackets mean that the parameter value is significantly different from 1 but not from the previous variable level.

In Model 2, all variables that directly or indirectly describe SES are included simultaneously while health variables are excluded. Naturally, the mortality differences between the levels of most of the variables get smaller than in Model 1 but, for example, income and wealth still have an independent significant impact on mortality. We see that when wealth and income are controlled for, higher education no longer has a positive separate impact. Men with an intermediate level of education even have a significantly higher mortality than lowly educated men (see discussion below). Having children reduces mortality for women but not for men. Further, the retired, the disabled and 
persons who are not in the labor force have a higher mortality than those who still work. Widows do not display a significantly different mortality from married persons. Men who are divorced or who have never married have a higher mortality whereas women in the same group have a lower one. Interestingly, the relative mortality risk of divorced or never married women turned from an insignificantly higher mortality according to the univariate results of Model 1 to a significantly lower mortality risk in Model 2. This finding may be due to a real disadvantage of females when married or due to an underrepresentation of institutionalized unhealthy women in the sample. The scope of my presentation does not allow for a detailed discussion of the reasons. But the fact that the sex difference emerges only after controlling for income and wealth may indicate that married women profit from higher material resources. Besides that, they do not have an advantage or may even have a disadvantage when being married net of the other factors in my analysis. Finally, income and wealth both have a strong diminishing impact on mortality.

One intermediate step between Model 2 and 3 is not shown here: it adds only health behavior to the SES variables and shows that the measured items of health behavior (physical activity, being an ex-smoker and being a smoker) changes the coefficients only slightly and do not remove the significance of any socioeconomic variables. This means that socioeconomic mortality differences to a large extent can not be explained by health behavior.

Model 3 is the full model, where the three health variables and also parents' mean age at death are added. We see that a high parents' mean age at death significantly reduces the mortality of women, and this supports the assumption that common genes in a family contribute to longevity. This interpretation is a valid one, not least because the inclusion of parents' education in the model as an indicator of their social status does not change the impact of their age at death (results not shown). Thus it is unlikely that in Model 3 parents' SES influences both the parents' mean age at death and the mortality of the respondent.

In the full model, wealth is no longer significant but most of the other socioeconomic mortality predictors still are. This indicates that the transition from a given health status to death is also influenced by the socioeconomic status. 
The results in table 1 are based on the assumption that the relative risks below or above 1 reduce or increase mortality as a multiplicative factor over the whole age range and across all levels of different other variables. This assumption is too simplistic. Therefore, the following interactions give a more accurate picture of the influence of selected variables.

\section{Figure 1: female mortality with interaction between education and wealth $($ low education and low wealth $=1)$}

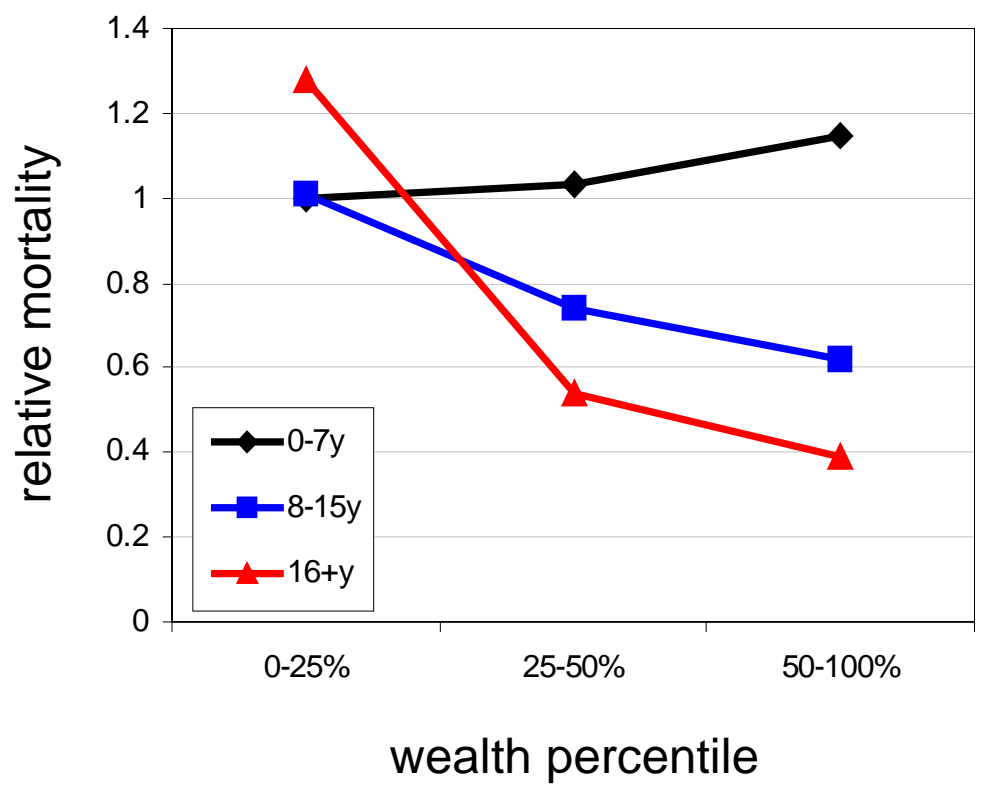

An interaction between education and wealth (Figure 1) shows that material wealth is only beneficial when combined with middle or higher education and higher education is beneficial only in combination with at least average wealth. When I use income instead of wealth in such a graph, the result is similar. This means that beyond the result of Model 2 , where the financial variables removed the positive influence of higher education, we now see that these two different resources have a complementary impact on mortality, i.e. both are necessary to have a mortality advantage. 
To address my central question whether socioeconomic mortality differences are stable or declining with increasing age, it is necessary to run interactions between age, i.e. the basic time variable of the model, and a variable for SES. In the following analysis, I will use income as an indicator for SES. This is because it has the highest separate impact on mortality (Table 1). The analysis with the other indicators for SES (not shown) sometimes show the same and sometimes less consistent results than with income but they never reveal much different or opposite patterns.

Figure 2 shows the mortality for men with interaction between age and income based on Model 2. Note that the graph does not show the increase of mortality with age but only the differences between the three income groups.

\section{Figure 2: male mortality with interaction between age and income $($ low income $=1)$}

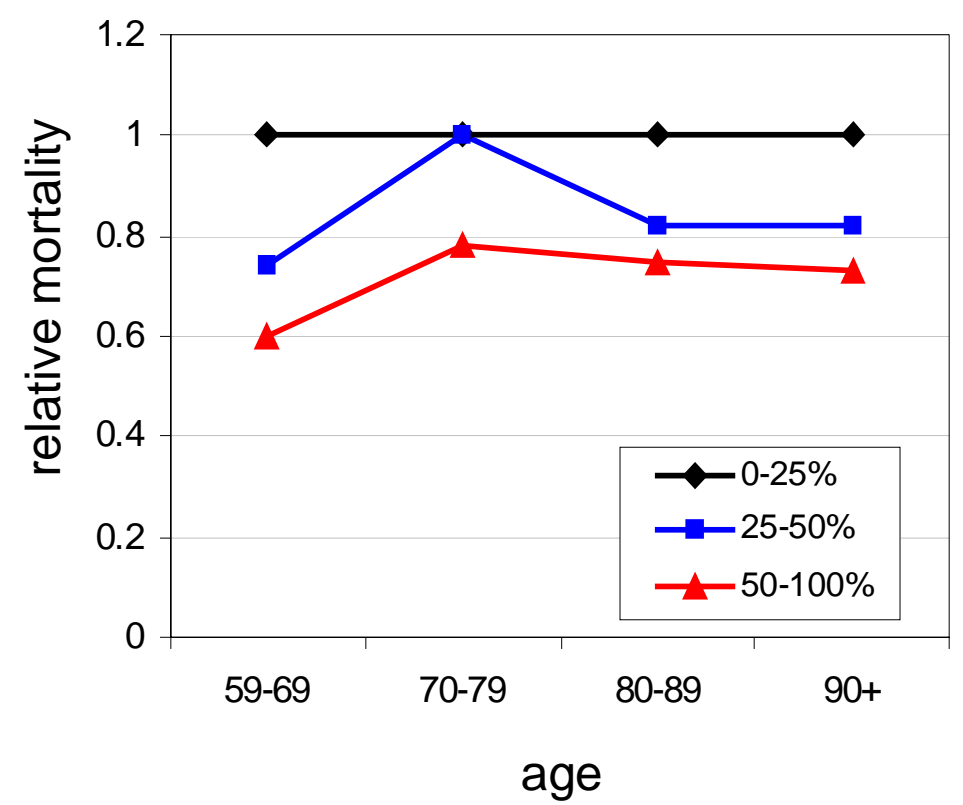

As we saw in table 1, men with the highest income have a significantly lower mortality. Those with a middle income also display a lower mortality. But this is only just significant. Far from being significant in this graph, however, are the fluctuations of differences over age groups. So I can conclude that mortality differences between income groups are stable over age. 
Figure 3 repeats figure 2 (thin lines) and shows the same interaction based on Model 3, which controls for the health variables (thick lines).

Figure 3: male mortality with interaction between age and income (low income $=1$ )

Controlled for all health variables (HC)

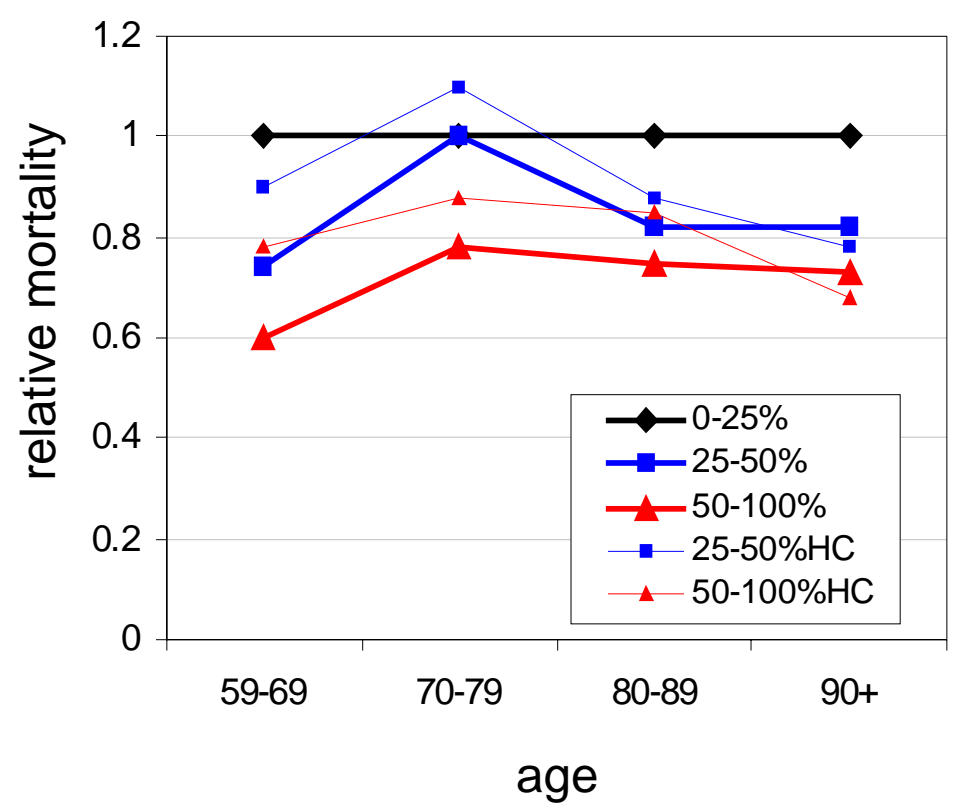

We see that when we control for health, the lines for middle and higher income get closer to the reference line. This effect is limited to younger age groups, with the consequence that mortality differences between poor and middle/high income groups tend to increase with age. But this increase is still far from being significant.

The next step is to address the problem of heterogeneity. Unfortunately, the model represented by the equation above, which includes the heterogeneity term $\mathrm{U}$, did not show the expected results. Neither aML nor STATA 8 was able to identify heterogeneity in the estimation procedure. This is most likely due to the sample size, an insufficient observation time or insufficient variation in time varying variables and not to the absence of heterogeneity in the sample. The assumption is that after controlling for heterogeneity, the relative risks would show a more realistic picture of determinants for individual mortality. Especially the mortality differences between social groups as shown in figure 2 and 3 are likely to be underestimated in higher ages because the population at high ages 
is more homogenous due to selective mortality. Thus, the true change of the impact of income over age for the individual can only be shown after a successful estimation of heterogeneity that in this case has to be postponed until better data are available. But since it is known in what direction the heterogeneity bias works, I can conclude from the results so far that the impact of SES is not decreasing with increasing age.

The next step shows how a health decline is affecting the impact of social status on mortality. Figure 5 shows an interaction between self-rated health and income. Age is still controlled for with four age groups, as it is in all models.

Figure 4: male mortality with interaction between income and health

(low income $=1)$

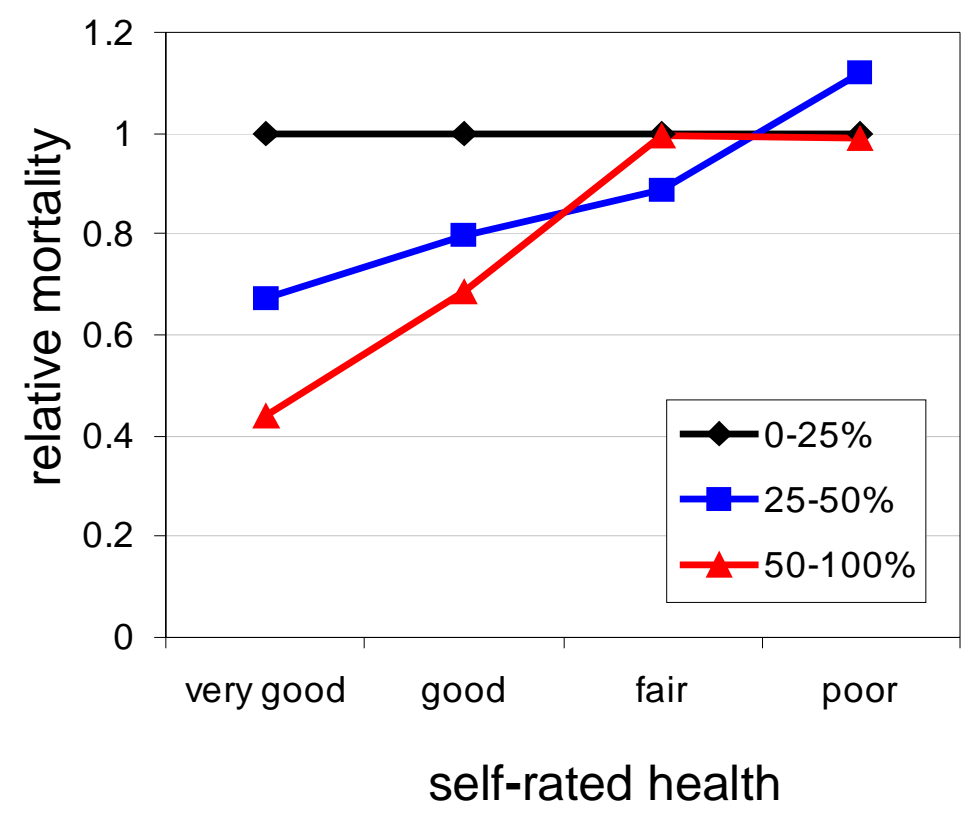

This significant interaction shows that income matters a lot when the person is in good health and that it has no impact when the person is in poor health. This means that poor health levels socioeconomic mortality differences.

If the health status is so important for the impact of SES on mortality, then the resulting question is whether the health decline with age is equally distributed between social groups, enough to result in a leveling of the mortality between social groups. I want to 
mention here three aspects of health distribution. First, health declines generally with age: The correlation between age and average health during the study is $0.20 * * *$ for selfrated health and $0.34 * * *$ for objective health. But despite of the general health decrease with increasing age, health is unequally distributed between income groups: Table 2 shows the other two aspects of the health distribution: first, the average self-rated health status and, second, the experience of a health deterioration, both by the three income groups from above. A transition from good to bad health here means that at the beginning of the observation period a person was in either the best or the second best category of either self-rated or objective health and has moved down at least two levels by the end of observation.

Table 2: Distribution and deterioration of health in different income groups, in \%

\begin{tabular}{|l|c|c|c|}
\hline $\mathrm{N}=9376$ & low income & middle income & high income \\
\hline $\begin{array}{l}\text { very good or good health at } \\
\text { the beginning of observation }\end{array}$ & 54.9 & 75.3 & 83.5 \\
\hline health deterioration & 18.3 & 13.9 & 10.0 \\
\hline
\end{tabular}

The differences in the table are significant at the 0.01 per cent level according to Pearson's chi-square test, which has been applied to the original two-way tables (not shown)

It is difficult to measure how large health differences are and even more so to measure how these differences change with age. But it is obvious that even if health generally declines with age, people with lower income initially have a lower health status and are more likely to experience a health decline.

Concerning the question whether socioeconomic mortality differences decline with age or not, it is, finally, important to see if the impact of the health status on mortality is stable across age groups. Figure 5 shows the interaction between age and health. 
Figure 5: male mortality with interaction between age and self-rated health $(\operatorname{very} \operatorname{good}=1)$

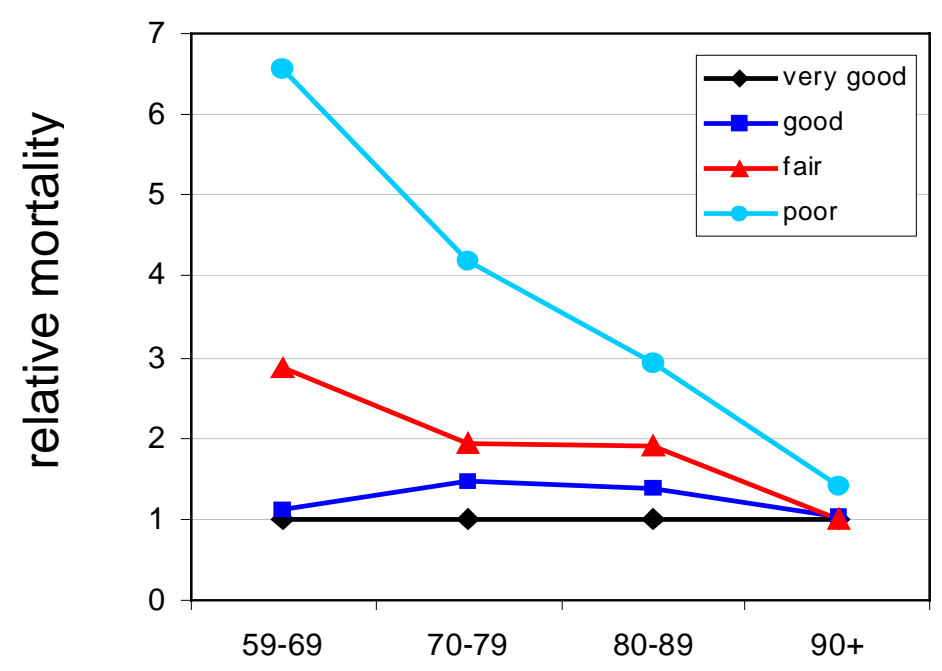

age

The interaction between age and self-rated health reveals that mortality differences between health groups are very large in younger age groups (age 59 to 69). When all socioeconomic variables and the other health variables are controlled for, men with a poor self-rated health status at this stage have more than a six-fold higher mortality than those with very good health $(\mathrm{RR}=6.6, \mathrm{CI}=4.4-9.8)$. These mortality differences converge very strongly in older age groups. This convergence is not due to self-estimation by the respondents because the same interaction based on the objective health measure shows an even stronger convergence (results not shown). Note that, naturally, it is possible to represent the interaction in figure 5 in absolute terms. Mortality then, would increase strongly with age and the distance between the lines, i.e. the absolute differences in the mortality risk, would only slightly decrease with age. But since I do not focus on the general increase in mortality with age, the chosen representation in figure 5 is more appropriate.

The main result with respect to the convergence of socioeconomic mortality differences is that these differences are stable across age. On the other hand, they converge with worsening health but health, in turn, assumes less importance for mortality in old age. 


\section{Discussion:}

The surprisingly higher mortality for men with an intermediate education has been observed also elsewhere (e.g. Liang et al. 2002) and it has been interpreted as an educational mortality crossover due to selective mortality. An alternative explanation is that, holding income constant in the model, higher education means that the aforementioned education is not translated into higher income. This could be because the person never got a job that matches his the educational level or he lost the job and thus experienced downward mobility, which may have been health related. This interpretation is supported by the fact that the excess mortality for middle educated men concentrates on the lower income and poorer health groups (results not shown). It also confirms that education is not beneficial on its own but only when combined with higher income. One possible conclusion is that education as a measurement of socioeconomic status has, besides several advantages, the disadvantage of being too stable across the life course.

The main result from the previous section, the convergence of socioeconomic mortality differences with worsening health but not with age, leads to the following interpretation. Age increases for everyone, i.e. a convergence of socioeconomic mortality differences with age would actually indicate that the impact of socioeconomic status decreases with age as a result of an equalizing welfare state policy or due to the temporal distance to unequal health experiences e.g. during work life (arguments 2 and 3 in the introduction). But instead, I find that socioeconomic mortality differences are stable across age groups (which supports arguments 5 to 7) and that instead of age poor health is the equalizer for social differences, maybe as a result of a universal shift from social to biological determinants of mortality when health decreases (argument 1).

This does not mean that social inequalities do no longer exist after health has become poor. It rather raises the question to what extent health differences are caused by SES and if social inequality in old age is incorporated in a more or less severe health decline and that therefore there is no longer social inequality in the transition from poor health to death. Thus, the question of social inequality in health is analogous to and becomes part of the question of social inequality in mortality. 
Research findings reveal clear socioeconomic health differences at old age (e.g. Huisman et al. 2003). The question of convergence or divergence with age is as unclear for health differences as it is for mortality differences. Ross and $\mathrm{Wu}$ (1996) find that health differences increase up to age 90 . In this study I can only make an attempt to analyze this question which reveals increasing health differences because from an already unequally distributed health at onset, the rate for health deterioration is also higher for low income groups (see table 2 and figure 6 below).

The central question of my research, i.e. whether socioeconomic mortality differences decrease with age or not has been answered by a modification of the question, namely by the identification of two aspects of increasing age both increasing mortality but with very different implications for the impact of SES on mortality. The first aspect, increasing numerical age, seems to be trivial but in fact some of the arguments used to support the hypothesis of mortality convergence refer solely to increasing age. These arguments can now be rejected. The second aspect is declining health, where my finding that money matters less in poor health rejects the assumption that money is of major importance to people in bad health to get good treatment to prevent them from dying. Concerning declining health, the problem remains: the theoretically simple scenario that a socially mixed sample will experience a simultaneous health decline that would level social differences in mortality will practically never happen. The health decline of upper class persons will either be delayed, will start on a higher health level or will be slower. Therefore, it is difficult to say if the potentially leveling impact of a health decline is actually effective. This is because poor health is likely to be to a large extent the result of low SES and thus it is unequally distributed. Figure 6 neglects the age dimension for a moment and shows the relation between health, SES and death, summarizing the findings from table 2 (transision A) and figure 4 (transitions B and C). 


\section{Figure 6: Transitions between good health and death}

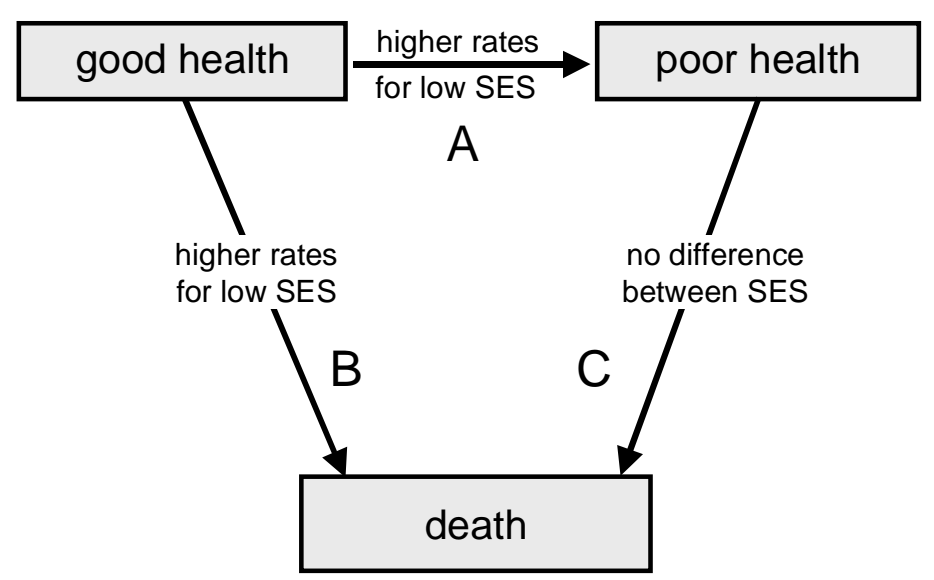

It is not obvious from my findings how age is intervening in this constellation. On the one hand, figures 2 and 3 show that the impact of social status is constant, on the other hand the impact of health on mortality decreases with age (figure 5). To answer this question, a very good measurement of socioeconomic health differences across age groups and maybe a multi-process model would be advantageous but both go beyond the scope of this study at the present stage.

One prerequisite for a good modeling of individual health trajectories is to have an observation time that is longer than 8 years and would cover a larger part of the age range from 59 to $100+$. This limitation may also be the reason for the failure to identify unobserved heterogeneity. This is because for such a procedure in a one level data set, one needs sufficient variation in time-varying variables. Another limitation is the underrepresentation of institutionalized persons, which possibly results in an underestimation of mortality differences. This is supported by Huisman et al. (2003) who tested and found that samples that exclude institutionalized persons indeed do underestimate health differences in older ages. 
Adams Peter, Hurd Michael D, Mcfadden Daniel, Marrill Angela, Ribeiro Tiago. (2002). "Healthy, wealthy, and wise? Tests for direct causal paths between health and socioeconomic status." Journal of Econometrics, 112, 1: 3-56.

Beckett Megan. (2000). "Converging health inequalities in later life - an artifact of mortality?" Journal of Health and Social Behaviour, 41: 106-119.

Breeze Elizabeth. (2000). Health inequalities persist into old age: results from the longitudinal study. In: Butler RN, Jasmin C. Longevity and Quality of Life: Opportunities and Challenges. New York et al.: Kluwer Academic Press / Plenum Publishers: 171-179.

Dannefer Dale. (2003). "Cumulative Advantage/Disadvantage and the Life Course: Cross-Fertilizing Age and Social Science Theory." Journal of Gerontology: Social Sciences, 58B, 6: 327-337.

Davey Smith George, Gunnell David, Ben-Shlomo Yoav. (2001). Life-course approaches to socio-sconomic differentials in cause-specific mortality. In: Leon DA, Walt G. Poverty, Inequality and Health: an International Perspective. Oxford: Oxford University Press: 88-124.

Doblhammer Gabriele. (2000) "Reproductive History and Mortality Later in Life: A Comparative Study of England \& Wales and Austria." Population Studies, 54, 2: 169-176.

Ferraro Kenneth F, Farmer Melissa M. (1996). "Double jeopardy, aging as leveler, or persistent health inequality? A longitudinal analysis of white and black Americans." Journal of Gerontologie: Social Sciences, 51b: 319-328.

Goldman Noreen. (2001). "Social inequalities in health: Disentangling the underlying mechanisms." Annals of the New York Academy of Sciences, 954, December: 118139.

Grundy Emily, Sloggett Andy. (2003). "Health inequalities in the older Population: the role of personal capital, social resources and socio-economic circumstances." Social Science and Medicine, 56, 935-947.

House James S, Kessler Ronald C, Herzog A Regula. (1994). "The social stratification of aging and health." Journal of Health and Social Behaviour, 35: 213-234.

Huisman Martijn, Kunst Anton E, Mackenbach Johan P. (2003). "Socioeconomic inequalities in morbidity among the elderly; a European overview." Social Science and Medicine, 57: 861-873.

Kunst Anton. (1997). Cross-National Comparisons of Socioeconomic Differences in Mortality. Rotterdam, Erasmus University: ThelaThesis. 
Liang Jersey, Bennet Joan, Krause Neal, Kobayashi Erika, Kim Hyekyung, Brown J. Winchester, Akiyama Hiroko, Sugisawa Hidehiro, Jain Arvind. (2002). "Old age mortality in Japan: Does the socioeconomic gradient interact with gender and age?" Journal of Gerontology: Social Sciences, 57b: 294-307.

Lillard Lee A., Panis Constantijn W A. (2003). "aML Multilevel Multiprocess Statistical Software Version 2.04." Los Angeles, California: Econware (http://www.appliedml.com).

Mackenbach Johan P, Kunst Anton E, Valkonen Tapani. (1999). "Socioeconomic inequalities in mortality among women and among men: An international study." American Journal of Public Health, 89: 1800-1806.

Marmot Michael G, Shipley Martin J. (1996). "Do socioeconomic differences in mortality persist after retirement? 25 year follow up of civil servants from the first Whitehall study." British Medical Journal, 313: 1177-1180.

Preston Samuel H, Elo Irma T. (1995). "Are educational differences in adult mortality increasing in the United States?" Journal of Aging and Health, 7: 476-496.

Ross Catherine E, Wu Chia-Ling. (1996). "Education, age, and the cumulative advantage in health." Journal of Health and Social Behaviour, 37: 104-120.

Smith James P, Kington Raynard S. (1997). Race, socioeconomic status and health in late life. In: Martin LG, Soldo BJ. Racial and Ethnic Differences in the Health of Older Americans. Washington: National Research Council: 105-162.

Soldo Beth J, Hurd Michael D, Rodgers Willard L, Wallace Robert B. (1997). "Assets and health dynamics among the oldest old: an overview of the AHEAD study." The Journals of Gerontology, 52b, Special Issue: 1-20.

StataCorp (2003). Stata Statistical Software: Release 8.0. College Station, TX: Stata Corportation (http://www.stata.com)

Vaupel James W, Manton Kenneth G, Stallard Eric. (1979). "The Impact of Heterogeneity in Individual Frailty on the Dynamics of Mortality." Demography, 16, 3: 439-454.

Warren John R, Kuo Hsiang-Hui. (2003). "How to Measure 'What People do for a Living' in Research on the Socioeconomic Correlates of Health." Annals of Epidemiology, 13, 5: 325-334. 